OPEN ACCESS

Edited by:

Pilar López-Larrubia,

Consejo Superior de Investigaciones

Científicas (CSIC), Spain

Reviewed by:

Afshin Namdar

University of Alberta, Canada

Kun Zheng,

Peking Union Medical College Hospital

(CAMS), China

${ }^{*}$ Correspondence:

YeXu

yexu@cqmu.edu.cn

Specialty section:

This article was submitted to

Cancer Imaging and Image-directed Interventions,

a section of the journal

Frontiers in Oncology

Received: 26 October 2020 Accepted: 14 December 2020 Published: 05 February 2021

Citation:

Wu C, Zhu W, Jin R, Ai H and Xu Y (2021) The MRI-Visible Nanocomposite Facilitates the Delivery and Tracking of siRNA Loaded DC Vaccine

in the Breast Cancer Model.

Front. Oncol. 10:621642. doi: 10.3389/fonc.2020.621642

\section{The MRI-Visible Nanocomposite Facilitates the Delivery and Tracking of siRNA Loaded DC Vaccine in the Breast Cancer Model}

\author{
Changqiang $\mathrm{Wu}^{1,2}$, Wencheng $\mathrm{Zhu^{3,4 }}$, Rongrong $\mathrm{Jin}^{3}$, Hua $\mathrm{Ai}^{3}$ and $\mathrm{Ye} \mathrm{Xu}{ }^{1 *}$ \\ ${ }^{1}$ Department of Radiology, Children's Hospital of Chongqing Medical University, National Clinical Research Center for Child \\ Health and Disorders, Ministry of Education Key Laboratory of Child Development and Disorders, Chongqing Key Laboratory of \\ Pediatrics, Chongaing, China, 2 Sichuan Key Laboratory of Medical Imaging and School of Medical Imaging, North Sichuan \\ Medical College, Nanchong, China, ${ }^{3}$ National Engineering Research Center for Biomaterials Sichuan University, Chengdu, China, \\ ${ }^{4}$ Shanghai Institute of Biochemistry and Cell Biology, Chinese Academy of Sciences, Shanghai, China
}

Dendritic cell (DC) vaccines have recently been developed for the treatment of various cancers but often do not function as well as expected, primarily due to the highly complex in vivo immune environment. This proof-of-principle study aimed to test the feasibility of modulating the in vivo behaviors of DC vaccines (DCVs) by introducing siRNA-laden magnetic resonance (MR) imaging nanovectors into cells, while providing visible information on their homing to lymph nodes. The N-alkyl-PEI2k-LAC/SPIO nanocomposites were prepared and characterized, showing favorable properties of siRNA transfection and MRI labeling efficiency in DCs. Cell viability assays revealed no observable effects on the survival and phenotype of DCs if the concentration of the complex was within $8 \mu \mathrm{g} \mathrm{Fe} / \mathrm{ml}$. An orthotopic mouse model of breast cancer was developed. The DCVs transfected with IDO siRNA contained nanocomposites were adoptively transferred to start the treatment. MR imaging clearly visualized the homing of DCVs into lymph nodes. At the end of the treatment, DCVs presented significantly better tumor suppression than DCs or PBS (P < 0.05). Generally, the N-alkyl-PEI2k-LAC/ SPIO nanocomposites represent a highly efficient MR imaging platform for siRNA transfection that is potentially useful for in vivo tracking of vaccine cells.

Keywords: dendritic cell, anticancer immunotherapy, gene transfection, nanocomposite, magnetic resonance imaging

\section{INTRODUCTION}

Dendritic cells (DCs) have been recruited as a cellular vaccine for tumor immunotherapy but their performance in vivo is generally unsatisfactory (1). Factors such as the weak antigenicity of tumors, failure of vaccine cells to migrate into lymph nodes (LNs) and drive $\mathrm{T}$ cell priming, and immune evasion of tumors, etc., are considered the culprits (2). Among these factors, tumor immune evasion may play a key role. Recent studies revealed that up-regulated expression of indoleamine 2, 3dioxygenase (IDO), a major rate-limiting enzyme of tryptophan catabolism, in DCs would induce 
naïve $\mathrm{CD}^{+} \mathrm{T}$ cells to differentiate into regulatory $\mathrm{T}$ cells ( $\mathrm{T}$ regs), thus impeding antitumor immunity (3). A small interfering RNA (siRNA) targeting IDO has been transfected into DCs to block the immunosuppression induced by the IDO mRNA, which exhibited potent tumor growth inhibition in animal models (4-6). As a promising RNA interference (RNAi) strategy, it involves the processes of delivering synthetic siRNAs into cells, incorporating these siRNAs into the silencing complex and subsequent degradation of sequencespecific mRNA. Unfortunately, exogenous siRNAs are easily degraded by nuclease in vivo, restricting the application of RNAi. Therefore, the preparation of an effective gene delivery system for loading and protecting gene fragments from nuclease damage and for improving gene transfection efficiency is very important (7). Previously, our research group synthesized an aqueous-phase magnetic resonance (MR) nanovector, N-alkylPEI2k/SPIO, with superior properties in subsequent experiments for MR imaging and as a nanocarrier for gene transfection $(8,9)$. Moreover, because the nanocomposites are modified by lactose, they hold superior MR imaging properties, improved biocompatibility by inducing protective autophagy and enhanced therapeutic immune activation of DC $(10,11)$. This study aimed to employ this lactosylated analog as a gene delivery platform for carrying IDO siRNA to transfect antitumor DC vaccines (DCVs) and to use it for the treatment of orthotopic 4T1 breast cancer in mouse models while using MR imaging to track the in vivo homing of DCVs to the draining LNs (Figure 1). To our best knowledge, this study utilizes a self-made, MRI-visible gene transfection vector to modulate the anticancer functions of DCV sy gene silencing while tracking their migration in vivo. Few studies have been reported on this topic previously.

\section{MATERIALS AND METHODS}

\section{Preparation of N-alkyl-PEI2k-LAC- Stabilized SPIO Nanoparticles}

Branched PEI2k (MW: $2 \mathrm{kD}$ ) was reacted with 1-iodododecane as previously reported (8). The product was treated with $\mathrm{NaOH}$ and dialyzed against water to obtain $\mathrm{N}$-alkyl-PEI2k upon freezedrying. The product N-alkyl-PEI2k was dissolved in methanol and added dropwise to a DL-glycidol methanol solution (12). The mixture was stirred for 3 days and dialyzed in water, yielding $\mathrm{N}$-alkyl-PEI2k-LAC.

Hydrophobic SPIO nanoparticles were synthesized using the methods described by Sun et al. (13). After drying under argon gas, SPIO nanoparticles were redispersed in chloroform and mixed with $\mathrm{N}$-alkyl-PEI2k-LAC at a mass ratio of 1:0.6. The mixture was transferred to water under sonication and shaken for $24 \mathrm{~h}$, followed by rotary evaporation to obtain chloroformfree $\mathrm{N}$-alkyl-PEI2k-LAC/SPIO nanocomposites.

\section{Characterization of $\mathrm{N}$-alkyl-PEI2k-LAC/ SPIO Nanocomposites}

Water-soluble N-alkyl-PEI2k-LAC/SPIO nanocomposites were characterized using dynamic light scattering (DLS) and electron microscopy (SEM). $T_{2}$ relaxation times were measured with a 1.5 T MR system (Siemens Sonata) at room temperature. Briefly, the Fe concentration of the nanocomposites in water was detected using atomic absorption spectrometry; then, gelatin phantoms containing gradient $\mathrm{Fe}$ concentrations of the nanocomposite were prepared. The $T_{2}$ relaxation time was detected using $M R$ imaging with a spin echo sequence (TR of 5,000 ms, TE ranging from 6 to $500 \mathrm{~ms})$. The relaxivity value $\left(r_{2}\right)$ was calculated from a

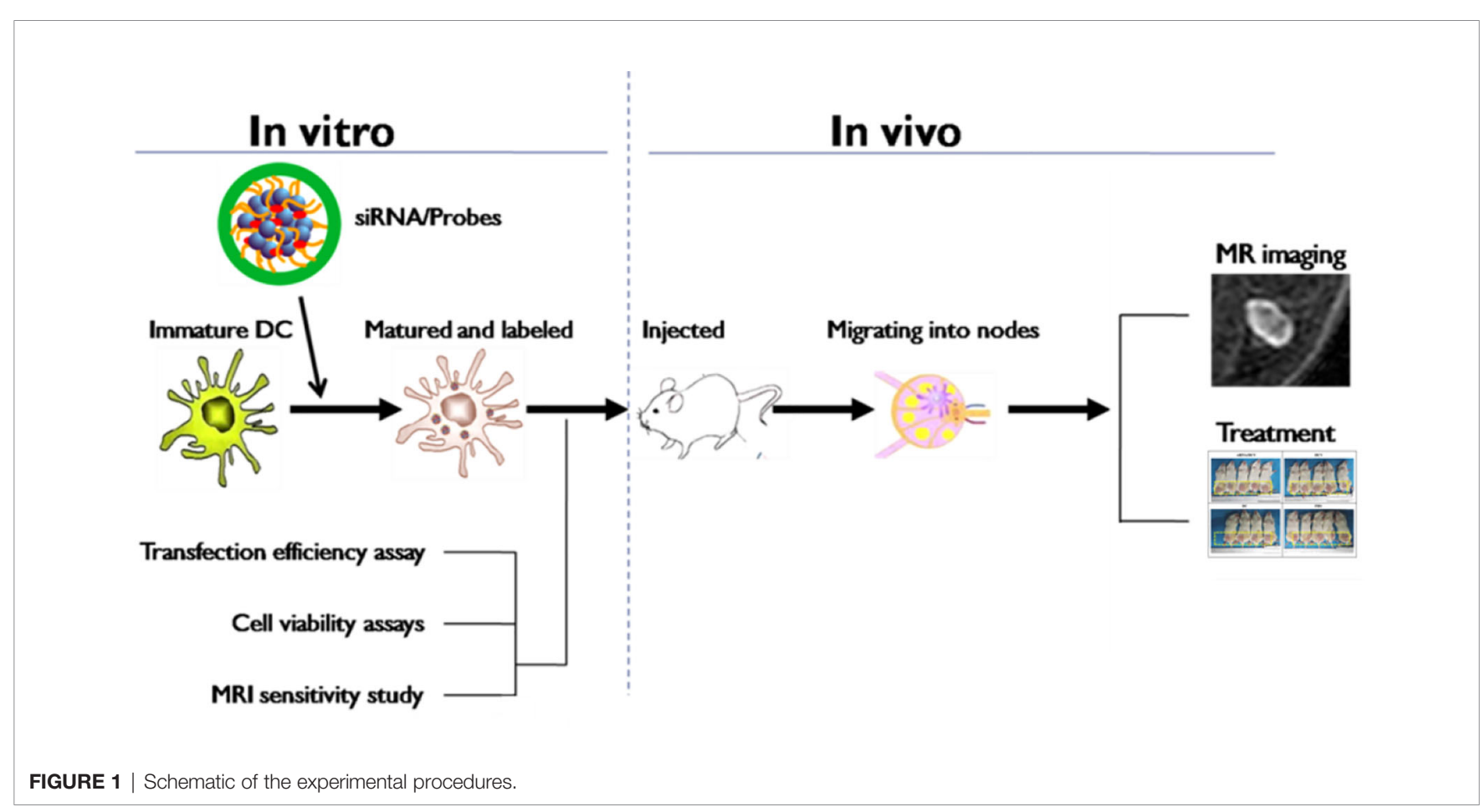


curve of $1 / \mathrm{T} 2$ relaxation time $\left(\mathrm{s}^{-1}\right)$ vs. the iron concentration (mM Fe) (12).

\section{Characterization of the N-alkyl-PEI2k- LAC/SPIO/siRNA Complex}

According to the target gene sequence selection methods described in literature (14), an siRNA targeting the IDO mRNA was synthesized by Ruibo Biological Co., Ltd. The antisense strand is 5'GUUCUAGAAGGAUCCUUGA3'. AlkylPEI2K-LAC/SPIO was mixed with the siRNA in PBS at different $\mathrm{N}: \mathrm{P}$ molar ratios $(0,2.5,5,7.5,10,12.5$, and 15 , respectively). The complexes were subjected to gel electrophoresis to detect the optimal binding concentration. Then, alkyl-PEI2k-LAC/SPIO and siRNA were mixed at an $\mathrm{N}: \mathrm{P}$ ratio of five for $20 \mathrm{~min}$. A gradient mass of heparin or serum was separately added to the mixture to test siRNA-release capacity and stability of the complex in serum.

\section{Preparation of Cells and siRNA- Transfected Dendritic Cell Vaccines}

The generation of murine DCs has been described in our previous report (12). Briefly, the bone marrow of Balb/C female mice was washed into RPMI-1640 medium and centrifuged to collect the cell pellet. The cells were cultured in flasks and stimulated with GM-CSF $(20 \mathrm{ng} / \mathrm{ml})$. On day 8 , the non-adherent population was harvested. LPS (100 ng/ml, SigmaAldrich) and TNF- $\alpha$ (20 ng/ml, Peprotech) were added and cells were cultured for another 2 days to obtain mature DCs. The purity of DCs was determined by measuring CD11c expression using fluorescence activated cell sorting (FACS).

The 4T1 cells were cultured in RPMI-1640 medium containing $10 \%$ fetal bovine serum and $5 \%$ penicillin-streptomycin at $37^{\circ} \mathrm{C}$ in the presence of $5 \% \mathrm{CO}_{2}$. Approximately 3 days later, the cells in the logarithmic growth phase were sub-cultured.

Using preparation methods described in the literature (15), the cultured $4 \mathrm{~T} 1$ breast cancer cells were lysed by subjecting them to six freeze-thaw cycles and a 30 min incubation in a water bath with ultrasound exposure before being passed over a $0.2 \mu \mathrm{m}$ filter on the benchtop to collect the filtrate. On day 8 of culture, DCs were co-incubated with the N-alkyl-PEI2k-LAC/ $\mathrm{SPIO} / \mathrm{siRNA}$ complexes at $6 \mu \mathrm{g} \mathrm{Fe} / \mathrm{ml}$ for $6 \mathrm{~h}$; the $4 \mathrm{~T} 1$ lysate was added at a ratio of 3:1 (4T1 cells:DCs) and incubated for $48 \mathrm{~h}$, and then cells were treated with LPS (100 ng/ml) for $12 \mathrm{~h}$ before harvest to promote maturation.

\section{In Vitro Transfection of N-Alkyl-PEI2k- LAC/SPIO/siRNA}

FITC-conjugated N-alkyl-PEI2k-LAC/SPIO was mixed with the siRNA at an N:P ratio of five for $20 \mathrm{~min}$ to determine if the complexes would be successfully engulfed by the cells. The complexes were collected and added to the culture medium of immature DCs at $6 \mu \mathrm{g} \mathrm{Fe} / \mathrm{ml}$. After a $6 \mathrm{~h}$ incubation, cells were collected and fixed, incubated with DAPI for $15 \mathrm{~min}$, and then washed with PBS. Fifty microliters of the cell suspension were dropped on a slide for confocal laser scanning microscopy (CLSM). For the analysis of the transfection efficiency, immature DCs were plated in a 48-well plate at a density of $2 \times 10^{5}$ cells $/ \mathrm{ml}$; then, $\mathrm{N}$ alkyl-PEI2k-LAC/SPIO/siRNA $(\mathrm{n}=5)$ was added at $\mathrm{Fe}$ concentrations of $0,2,4,6,8,10$, and $12 \mu \mathrm{g} / \mathrm{ml}$. After a $6 \mathrm{~h}$ incubation the plates were cooled to room temperature, the iron reaction reagent was added, and the absorbance was read at $570 \mathrm{~nm}$ using a plate reader (Varioskan Flash, Thermo Scientific). The Nalkyl-PEI2k-LAC/SPIO/siRNA complexes were added to immature DCs at $6 \mu \mathrm{g} \mathrm{Fe} / \mathrm{ml}$ to determine potential unwanted effects on DCs. Six hours later, the medium was replaced with three volumes of 4T1 breast tumor cell lysate, as described in detail below. After a $48 \mathrm{~h}$ incubation, DCVs transfected with N-alkyl-PEI2k-LAC/SPIO/ siRNA complexes were obtained. The siRNA-laden DCVs were collected and transferred to a $1.5 \mathrm{ml}$ centrifuge tube, with siRNAfree and immature DCs and siRNA-free DCVs as controls, and then incubated with antibodies to detect the expression of the surface molecular markers MHC-II, CD11c, CD80, CD86, and CCR7 using FACS.

\section{Western Blotting}

On day 8 of culture, DCs were divided into two groups, one was incubated with IFN- $\gamma(200 \mathrm{U} / \mathrm{ml})$, LPS (100 ng/ml) and TNF- $\alpha(20$ $\mathrm{ng} / \mathrm{ml})$, and the other was treated only with LPS $(100 \mathrm{ng} / \mathrm{ml})$ and TNF- $\alpha(20 \mathrm{ng} / \mathrm{ml})$. Forty-eight hours later, the cells were collected for Western blotting to analyze the expression of IDO (16).

\section{Dendritic Cell Vaccine Treatment Protocols for 4T1 Mice and In Vivo Magnetic Resonance Imaging}

After hair removal, the mammary fat pads of 6-week-old Balb/C female mice were injected with $1 \times 10^{6} 4 \mathrm{~T} 1$ cells. Vaccines were injected using previously reported procedures (17). Briefly, TNF- $\alpha(100 \mathrm{ng} / \mathrm{ml})$ was subcutaneously injected into the left posterior footpad of the mice to pre-sensitize the local tissues. After 48 h, PBS, DC, DCV, and IDO siRNA-laden DCV were injected at the same sites, respectively. About $100 \mu$ of PBS, $3 \times$ $10^{6}$ cells/ft of DC, or $3 \times 10^{6}$ cells/ft DCV were injected on the day of tumor inoculation and thereafter repeated once a week for two times. Mice with breast cancer were randomly grouped into four ( $\mathrm{n}=5$ mice per group). The following treatment regimens were planned: (1) PBS injected into the left footpad; (2) N-alkylPEI2k-LAC/SPIO DCs, activated by LPS (100 ng/ml) and TNF- $\alpha$ (20 ng/ml), injected into the left footpad; (3) N-alkyl-PEI2kLAC/SPIO DCVs injected into the left footpad; and (4) IDO siRNA-laden DCVs injected into the left footpad. The mice were imaged under a Philips 3.0 T MR scanner using a $25 \mathrm{~mm}$ small animal coil at $24 \mathrm{~h}$ before and $48 \mathrm{~h}$ after each injection. Echoes of popliteal lymph nodes (LNs) were measured primarily using a $T_{2}$-wighted fast spin echo $(\mathrm{TSE})$ sequence $(\mathrm{TR}=2300 \mathrm{~ms}, \mathrm{TE}=$ $121 \mathrm{~ms}$, matrix $=148 \times 148$, slice thickness $=0.6 / 0.0 \mathrm{~mm}, \mathrm{FOV}=$ $30 \mathrm{~mm}$, flip angle $=90^{\circ}$, NSA $=10$ ).

\section{Evaluation of the Therapeutic Effects of Indoleamine 2, 3-Dioxygenase siRNA- Laden Dendritic Cell Vaccines on Tumors}

After the inoculation of $4 \mathrm{~T} 1$ cells, the tumor sizes were measured on day 3 and repeated every 3 days thereafter for 4 repeats. 
The tumor volume $S$ was calculated using the formula, $S=0.5 \times$ $a^{2} \times b$, where $a$ represents the short diameter of the tumor and $b$ represents the long diameter of the tumor (18).

\section{Statistical Analysis}

SPSS 13.0 software was employed for statistical analyses. Independent sample T-test was used to test the statistical significance of differences between two groups, and one-way analysis of variance was used to determine the statistical significance of differences among more groups. $P<0.05$ indicates a significant difference.

\section{RESULTS}

\section{Characterization of the Nanocomposites}

The chemical structures of amphiphilic N-alkyl-PEI2k-LAC and $\mathrm{N}$-alkyl-PEI2k were characterized using ${ }^{1} \mathrm{H}$ NMR and elemental analysis (Figure 2). N-alkyl-PEI2k: ${ }^{1} \mathrm{H}$ NMR (400 MHz, $\mathrm{CDCl}_{3}$ ) $\delta 3.15-2.21\left(\mathrm{~m},-\mathrm{CH}_{2} \mathrm{CH}_{2} \mathrm{NH}-,-\mathrm{CH}_{2} \mathrm{CH}_{2}\left(\mathrm{CH}_{2}\right)_{9} \mathrm{CH}_{3}\right), 1.41$ (br, $\left.-\mathrm{CH}_{2} \mathrm{CH}_{2}\left(\mathrm{CH}_{2}\right)_{9} \mathrm{CH}_{3}\right), 1.25\left(\mathrm{~s},-\mathrm{CH}_{2} \mathrm{CH}_{2}\left(\mathrm{CH}_{2}\right)_{9} \mathrm{CH}_{3}\right), 0.88$ (t, $\left.-\mathrm{CH}_{2}\left(\mathrm{CH}_{2}\right)_{10} \mathrm{CH}_{3}\right)$; Elemental analysis: $\mathrm{C}, 56.489 \%$; , 19.07\%; H, 9.209\%. N-alkyl-PEI2k-LAC: ${ }^{1} \mathrm{H}$ NMR $(300 \mathrm{MHz}$, DMSO) $\delta$ 4.55-3.21 (m, LAC), 3.19-2.25 (m, $-\mathrm{CH}_{2} \mathrm{CH}_{2} \mathrm{NH}-$, $\left.-\mathrm{CH}_{2} \mathrm{CH}_{2}\left(\mathrm{CH}_{2}\right)_{9} \mathrm{CH}_{3}\right), 1.39$ (br, $\left.-\mathrm{CH}_{2} \mathrm{CH}_{2}\left(\mathrm{CH}_{2}\right)_{9} \mathrm{CH}_{3}\right), 1.22$ (s, $\left.-\mathrm{CH}_{2} \mathrm{CH}_{2}\left(\mathrm{CH}_{2}\right)_{9} \mathrm{CH}_{3}\right), 0.84\left(\mathrm{~s},-\mathrm{CH}_{2}\left(\mathrm{CH}_{2}\right)_{10} \mathrm{CH}_{3}\right)$. Elemental analysis: C, 46.188; N, $11.499 \%$;, $10.223 \%$. Grafting ratio of alkyl and lactose were separately 12.1 and $10.3 \%$, calculated upon elemental analysis results.
The monodisperse SPIO nanocrystals and amphiphilic material (mass ratio: $\mathrm{N}$-alkyl-PEI2k-LAC : SPIO =0.6) were used to form $\mathrm{N}$-alkyl-PEI2k-LAC/SPIO nanocomposites in the water phase. The nanocomposites dispersed in water stably, with a diameter of $83.0 \pm 26.5 \mathrm{~nm}$ obtained using DLS (Figure 3). The dry sample presented as spherical particles in SEM images, and SPIO nanocrystals aggregated into nanoclusters in the composites in TEM images (Figure 4). The surface charge of the SPIO nanocomposites remained positive with a zeta potential of $34.6 \pm 1.1 \mathrm{mV}$, a value that is lower than $\mathrm{N}$-alkyl-PEI2k/SPIO nanocomposites (approximately $40 \mathrm{mV}$ ), due to lactose partially shielding the positive electric charge on PEI.

Gelatin phantoms containing gradient Fe concentrations of the nanocomposite were detected using spin echo $T_{2} \mathrm{WI}$ at different echo times with a clinical 1.5 T MR imager at room temperature to measure the $T_{2}$ relaxivitiy of the nanocomposites. Signal intensities (SIs) were acquired to calculate the $T_{2}$ relaxivitiy $\left(r_{2}\right)$ of the nanocomposites of $481.3 \mathrm{mM}^{-1} \mathrm{~s}^{-1}$ (Figure 5).

\section{Characterization of the $\mathrm{N}$-alkyl-PEI2k- LAC/SPIO/siRNA Complex}

$\mathrm{N}$-alkyl-PEI2k-LAC/SPIO was incubated with the siRNA at different $\mathrm{N}: \mathrm{P}$ molar ratios and then subjected to gel electrophoresis. With the increase in the $\mathrm{N}: \mathrm{P}$ ratio, siRNA electromigration was increasingly blocked, and electromigration was completely blocked at an N:P ratio $\geq 5$. Based on these results, the siRNA was successfully bound to the surface of the nanocomposites (Figure 6A).

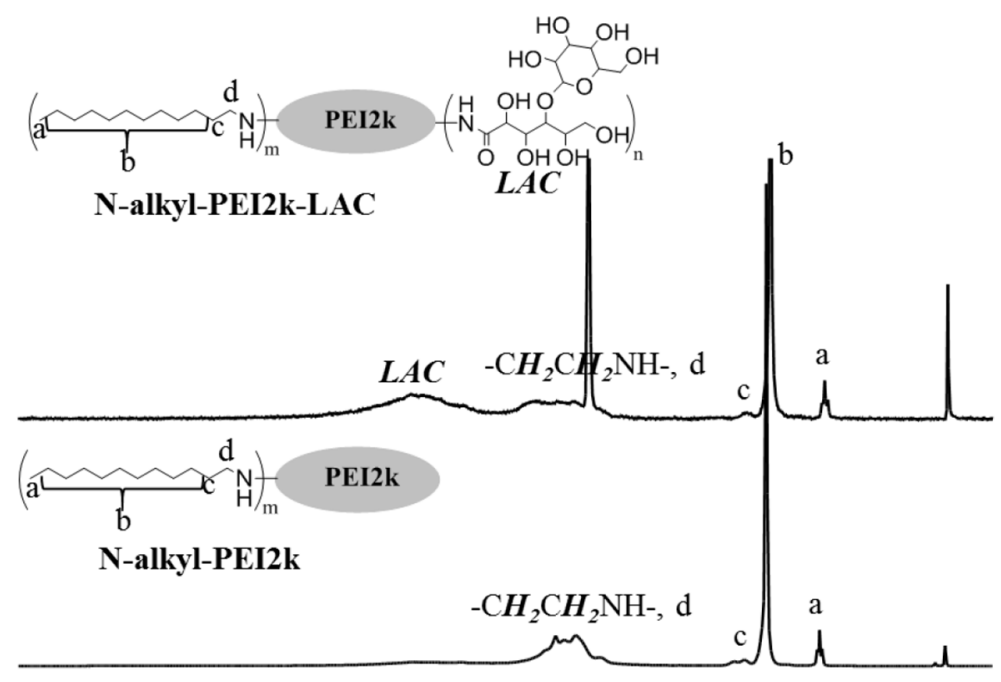

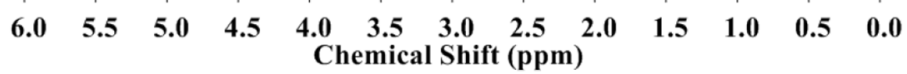

FIGURE 2 | ${ }^{1} \mathrm{H}$-NMR spectra of N-alkyl-PEI2k-LAC (DMSO) and N-alkyl-PEI2k (CDCl3). 


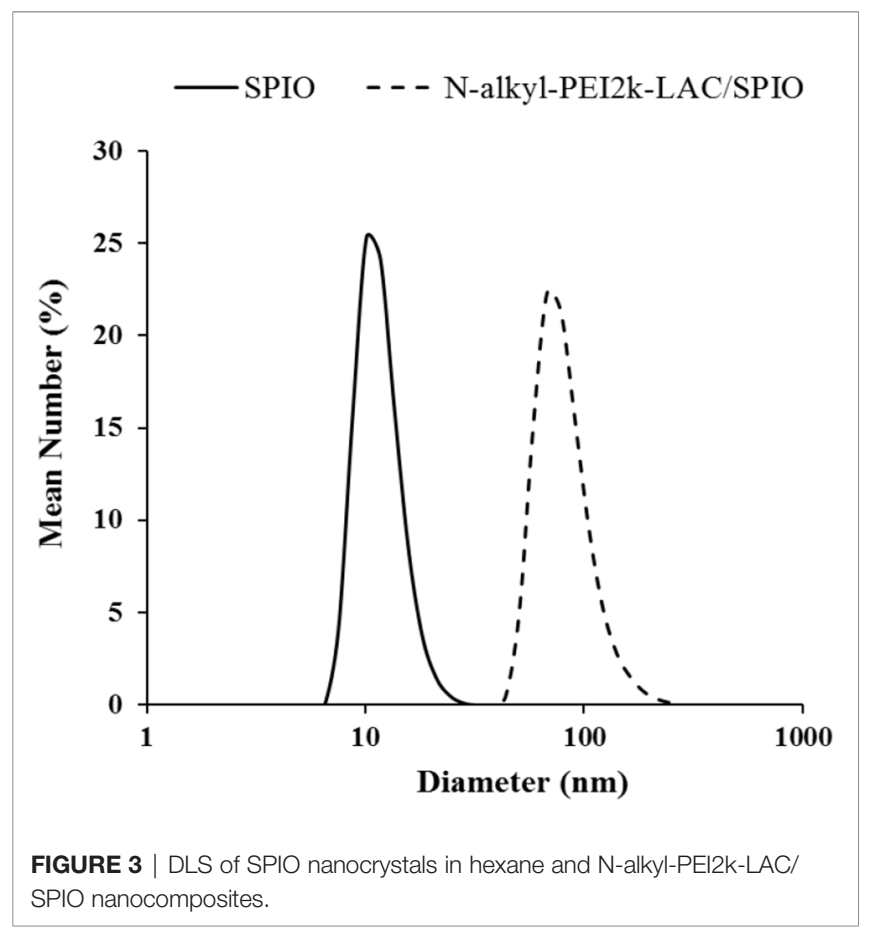

In a heparin decomplexation assay, N-alkyl-PEI2k-LAC/ SPIO/siRNA complexes (N:P = 5) were loaded on agarose gel. The electrophoresis assay showed that the siRNA was released from the complexes when heparin was added. At a heparin: siRNA mass ratio $\geq 5$, the released siRNA tended to be stable and its concentration no longer increased (Figure 6B).

In a serum stability assay, N-alkyl-PEI2k-LAC/SPIO/siRNA complexes $(\mathrm{N}: \mathrm{P}=5)$ and the unbound siRNA were separately incubated with $50 \%$ fetal bovine serum (FBS) for different periods. As a result, the siRNA in the complexes was substantially more stable in serum than the unbound siRNA; and even after a $24 \mathrm{~h}$ incubation, the siRNA still stably resided on the nanocomposite surface without observable degradation (Figure 6C).

\section{In Vitro Transfection of N-alkyl-PEl2k- LAC/SPIO/siRNA}

FITC-conjugated N-alkyl-PEI2k-LAC/SPIO was mixed with the siRNA; then, the complexes were transfected into DCs by coincubation. CLSM revealed clusters of green fluorescent particles around the blue-stained nuclei. Differential interference contrast (DIC) imaging further showed pseudopodia of the cells, suggesting that they are siRNA-laden DCs (Figure 7).

The intracellular Fe content was measured using a colorimetric ferrozine assay. DCs took up the N-alkyl-PEI2k-LAC/SPIO/siRNA complexes in a time- and dose-dependent manner (Figure 8). After a $6 \mathrm{~h}$ incubation, the intracellular Fe content tended to be stable, indicating that at least $6 \mathrm{~h}$ is necessary for sufficient transfection. A slightly lower concentration of the N-alkyl-PEI2k-LAC/SPIO/ siRNA complexes, $6 \mu \mathrm{g} \mathrm{Fe} / \mathrm{ml}$, was adopted for subsequent in vivo studies to ensure ample antigen loading.

The surface phenotype of DCs was detected using a FACS assay to probe possible adverse effects of the transfection process on DC maturation. CD11c is a marker of the purity of DCs. Our culture produced approximately $90 \%$ CD 11 c positive cells. Four other biomarkers, MHC-II, CD80, CD86, and CCR7, showed similar expression on siRNA-laden mature DCs to siRNA-free mature DCs, but the expression of CD80, CD86, and CCR7 was significantly higher than on immature DCs $(P<0.05$ for all of them), suggesting the excellent biosafety of transfection (Figure 9).

\section{Western Blot}

Western blotting was performed on two groups of mature DCs treated with or without IFN- $\gamma$ to analyze the expression of the target protein IDO in DCs. Replicate experiments revealed that IFN- $\gamma$-induced DCs expressed slightly higher levels of IDO (Figure 10).
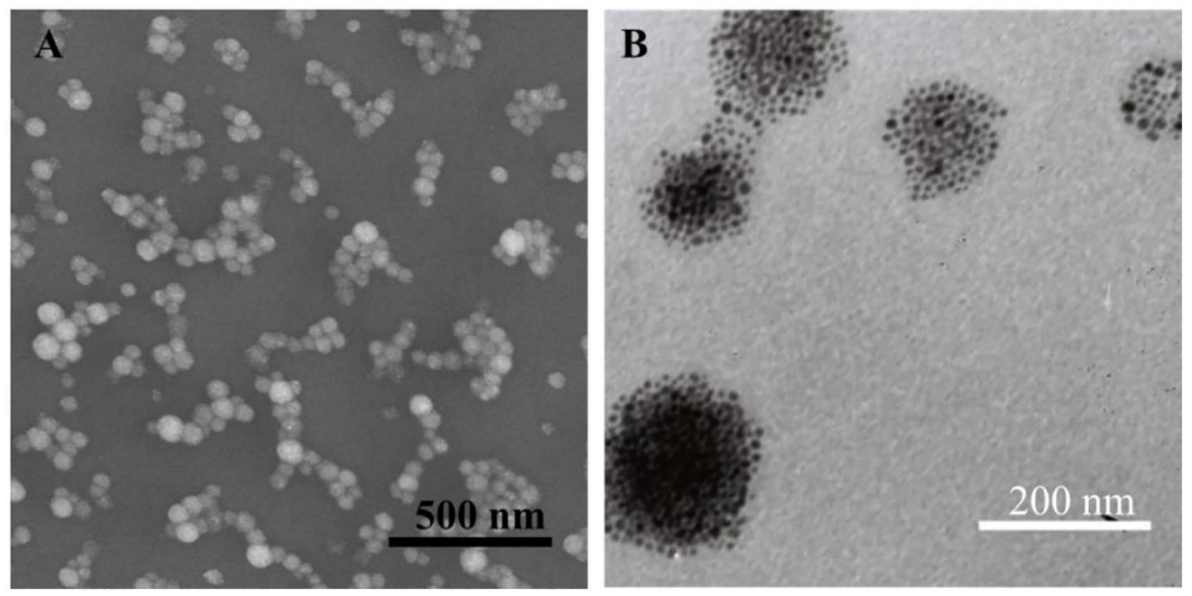

FIGURE 4 | SEM (A) and TEM (B) images of N-alkyl-PEl2k-LAC/SPIO nanocomposites. 


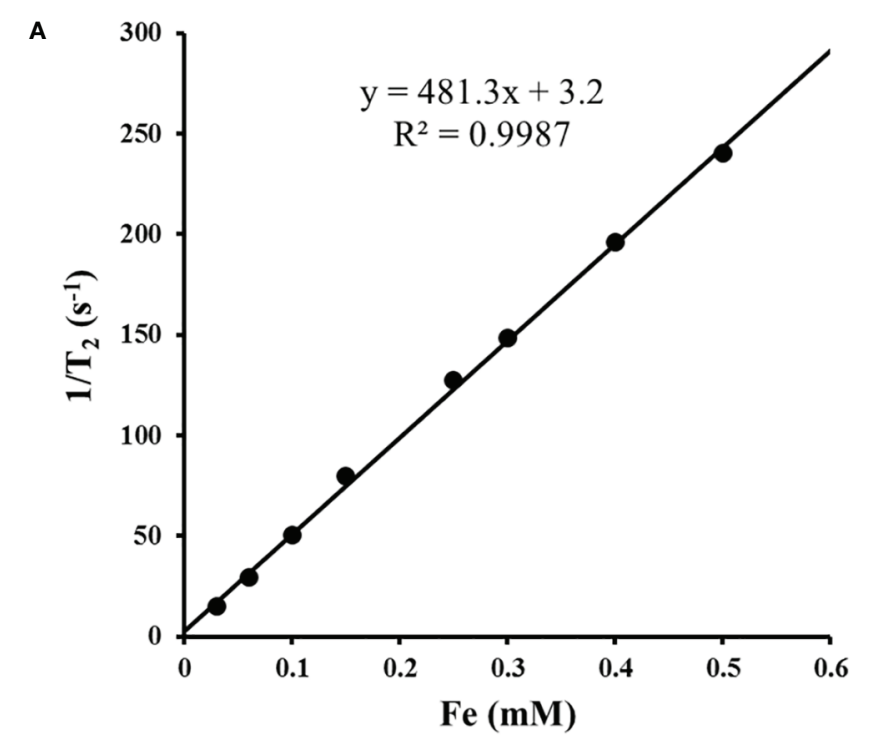

B

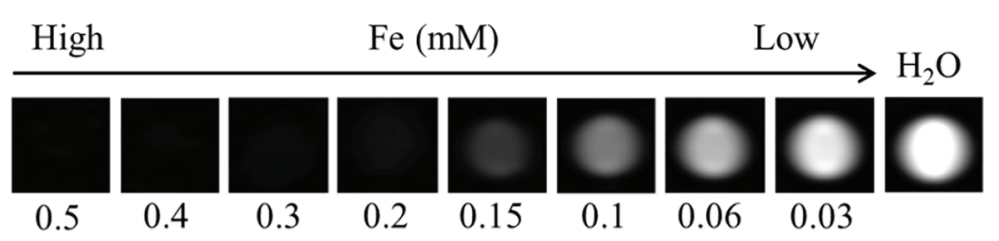

FIGURE 5 | $T_{2}$ relaxation rate as a function of the Fe concentration for $\mathrm{N}$-alkyl-PEI2k-LAC/SPIO nanocomposites at $1.5 \mathrm{~T}$ (A); $T_{2}$-weighted MR images of $\mathrm{N}$-alkyl$\mathrm{PEI}$ Kk-LAC/SPIO nanocomposites in water (B).

\section{In Vivo Magnetic Resonance Imaging of Tumors Treated With Indoleamine 2, 3- Dioxygenase siRNA-Laden Dendritic Cell Vaccines}

MR imaging was performed to observe whether the injected vaccines migrated to the draining lymph nodes as expected and resulted in changes in SI. MR imaging of bilateral popliteal lymph nodes was performed on the four groups of tumorbearing mice before and after each footpad injection. Vaccines were injected weekly for three injections, and MR images were correspondingly obtained at two time points, immediately before and $48 \mathrm{~h}$ after each injection. Left popliteal nodes of all DC groups were gradually enlarged. In particular, the nodes were strikingly enlarged 1 week after the first injection. On the TSE images captured $48 \mathrm{~h}$ after the first injection, the signal was clearly reduced within the nodes' central zone of all DC groups; at $48 \mathrm{~h}$ after the second or third injections, a focal signal reduction was still visible, but not as clear as after the first injection (Figure 11).

\section{Evaluation of the Antitumor Therapeutic Effects}

By the end of the experiment, all mice survived, except for one mouse in the N-alkyl-PEI2k-LAC/SPIO DC group that died unexpectedly. After the inoculation of $4 \mathrm{~T} 1$ tumor cells, tumor volume was measured and calculated once every 3 days for five measurements. Tumor sizes increased gradually, regardless of treatment with PBS, DC, DCVs or IDO siRNA-laden DCVs. Notably, tumors in the PBS group grew the fastest, followed by the tumors in the DC group. Tumors in the two vaccine groups grew at similar rates (Figure 12). The tumor volume was analyzed using ANOVA, and the IDO siRNA-laden DCV group had comparable tumor volumes to the DCV group, but significantly larger volumes than the PBS or the DC group (P $<0.05$ for both) (Figure 13).

\section{DISCUSSION}

\section{$\mathrm{N}$-alkyl-PEI2k-LAC/SPIO as Magnetic Resonance Imaging-Visible Gene Nanovector Showed Favorable Properties}

This study utilizes lactobionic acid to superficially modify $\mathrm{N}$ alkyl-PEI2k/SPIO. The generated nanocomposites possess favorable physicochemical and MR imaging properties, as confirmed by ${ }^{1} \mathrm{H}$ NMR, DLS, SEM and MR imaging. We studied their capabilities of binding or releasing the siRNA, the serum stability of the siRNA in the complexes, gene transfection efficiency, and their effects on DCs to obtain a better 


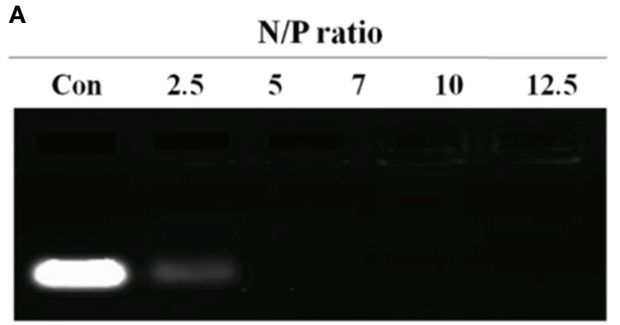

B

Heparin/siRNA (weight ratio)

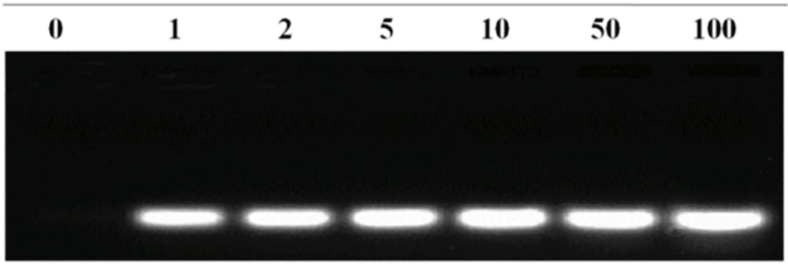

C

$50 \%$ serum

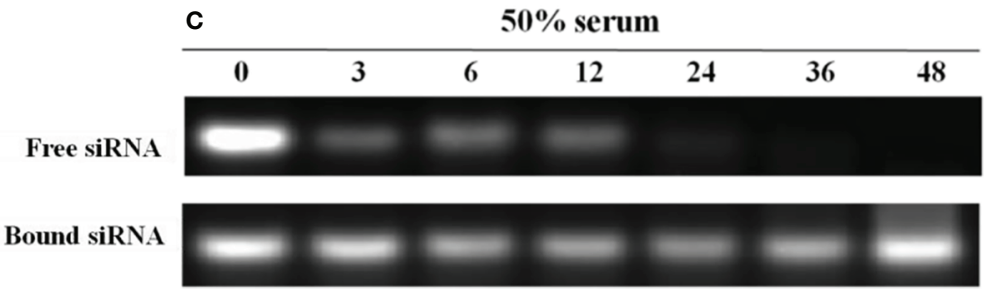

FIGURE 6 | Agarose gel electrophoresis analysis of the N-alkyl-PEI2k-LAC/SPIO/siRNA complexes. (A) At an N:P ratio $\geq 5$, the nanocomposites completely bound the siRNA. (B) At a heparin/siRNA mass ratio $\geq 5$, a substantial amount of the siRNA was released. (C) Serum stability of the siRNA bound to or free from N-alkylPEI2k-LAC/SPIO. The free siRNA or N-alkyl-PEI2k-LAC/SPIO/siRNA complexes were incubated with $50 \%$ serum for the indicated times. Heparin was used to release the bound siRNA from the nanocomposites.

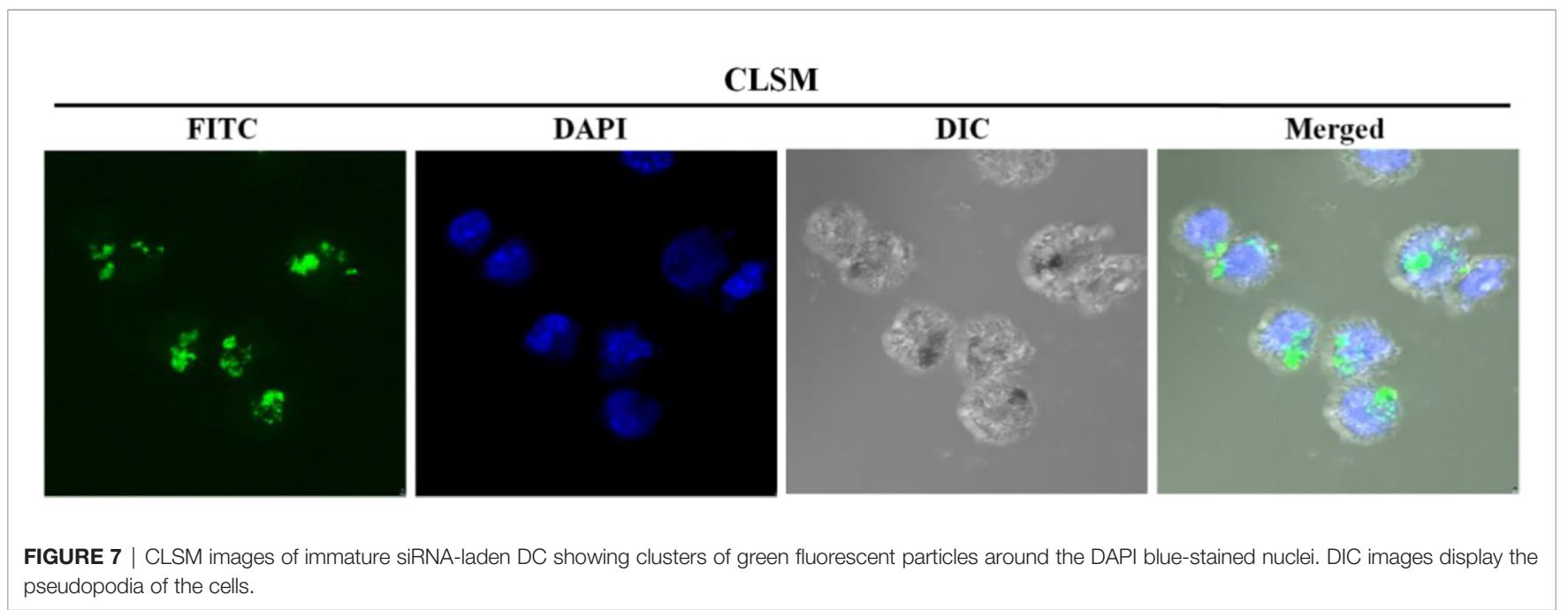

understanding of their biological properties as nanocarriers for gene transfection. Similar to the previously reported N-alkylPEI2k/SPIO, at an N:P ratio $\geq 5$, N-alkyl-PEI2k-LAC/SPIO almost completely bound the siRNA, suggesting that the lactose modification method has little effect on the ability of the nanocomplex to bind to siRNA $(9,19)$. At a heparin/siRNA mass ratio $\geq 1$, the siRNA was fully released to silence the target genes. Moreover, a high concentration of the siRNA persisted in serum even at 48 after the interaction with $\mathrm{N}$-alkyl-PEI2k-LAC/ SPIO, indicating that the nanocomposites provide reliably 

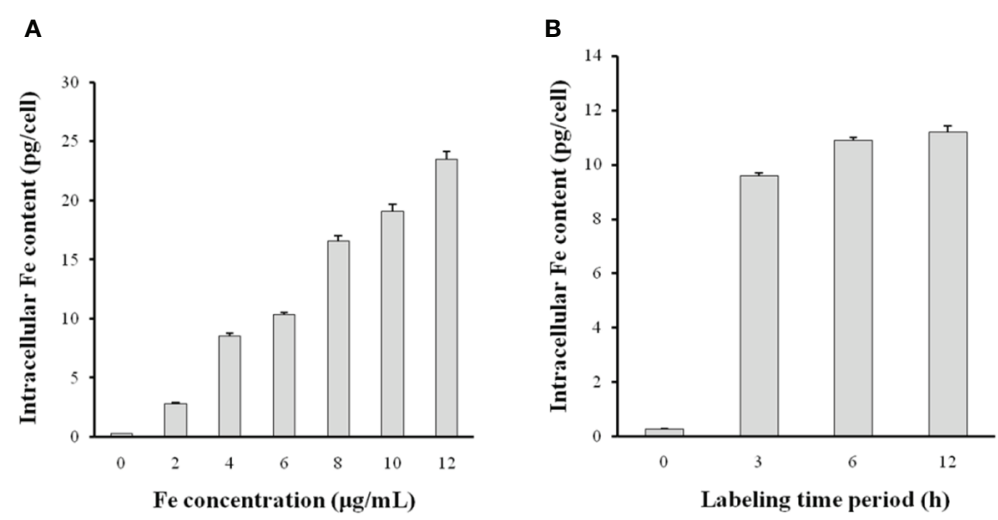

FIGURE 8 | The siRNA transfection efficiency was altered by the N-alkyl-PEl2k-LAC/SPIO/siRNA concentration (A) and transfection time period (B). Higher concentrations of the complexes or a longer transfection time period increases the Fe content within DCs $(n=5)$.
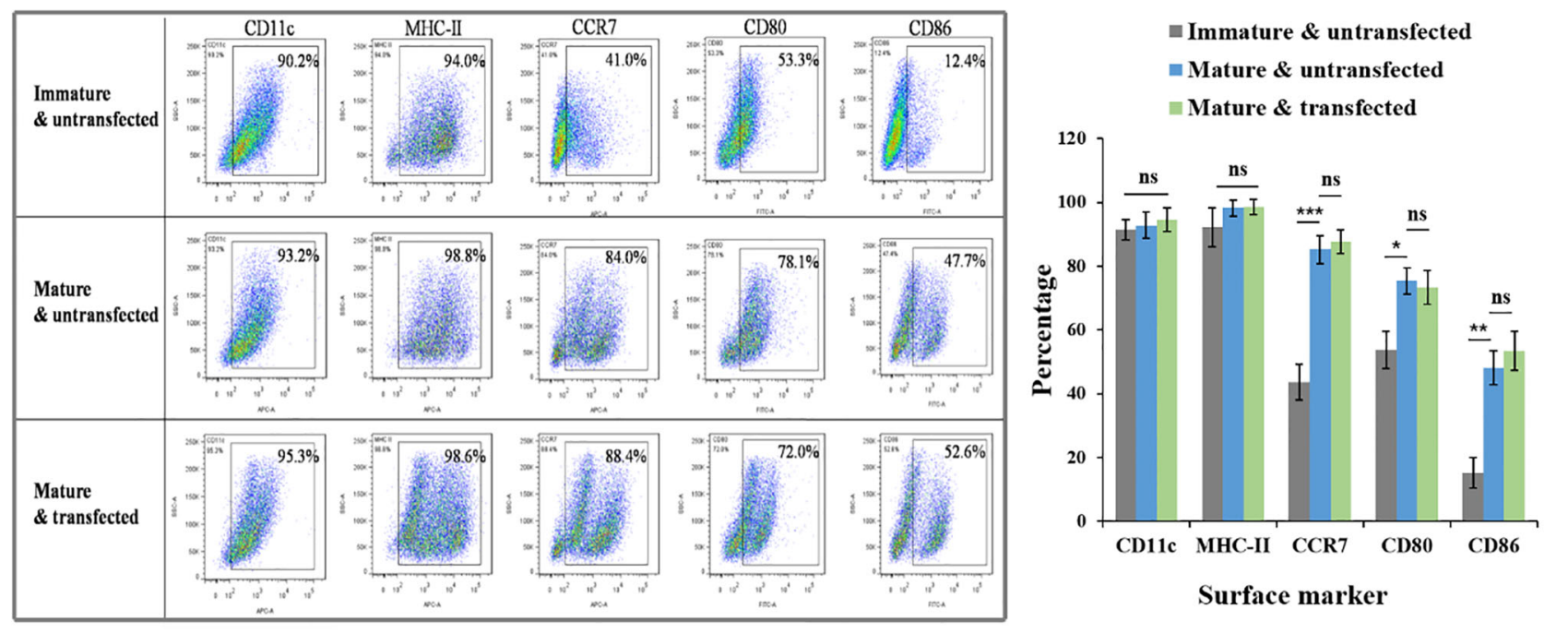

FIGURE 9 | Effects of N-alkyl-PEI2k-LAC/SPIO/siRNA transfection on the maturation phenotype and marker expression of DCs. FACS assay showed that siRNAladen mature DCs expressed similar levels in biomarkers MHC-II, CD80, CD86, and CCR7 to siRNA-free mature DCs, but significantly higher levels than immature DCs in CCR7, CD80 and CD86. A two-tailed unpaired Student's t test was performed for two-group comparisons, and the results with significant difference were marked in ${ }^{*} P<0.05,{ }^{\star \star} P<0.01$, or ${ }^{\star \star *} P<0.001$, respectively. ns, no significance.

protect the siRNA from enzymolysis in vivo. Both CLSM and intracellular $\mathrm{Fe}$ content measurements showed that the transfection of N-alkyl-PEI2k-LAC/SPIO/IDO-siRNA was successful and depended on both the time and concentration. The molecular phenotype of a cell, to some extent, represents its properties and functions. FACS results showed that expression of four important molecular markers (MHC-II, CD80, CD86, and CCR7) on DCs transfected with the siRNA complex at $6 \mu \mathrm{g} \mathrm{Fe} /$ $\mathrm{ml}$ was not distinctly different from siRNA-free mature DCs. In recent years, some authors have noted that nanoparticles often facilitated maturation of DCs $(20,21)$. In a previous study, we also found that glycoidol-modified alkyl-PEI/SPIO nanocomposites up-regulated expression of MHC-II, CD80, CD86, and CCR7 if DCs were labeled prior to maturation (12). When DCs are matured, they exhibit function reduction in capturing antigens and function enhancement in migration and antigen-presentation. We do not think the effects of nanocomposites to DCs are conducive because the non-specific stimulation may lead to impaired capture of the antigens (12). In current study, the effect was not so evident for N-alkyl-PEI2kLAC/SPIO nanocomposites, as shown by the FACS results. The improved properties perhaps partly attribute to the lactose modification that reduced surface cations of the nanocomposites. DCs are the cells highly sensitive to external 


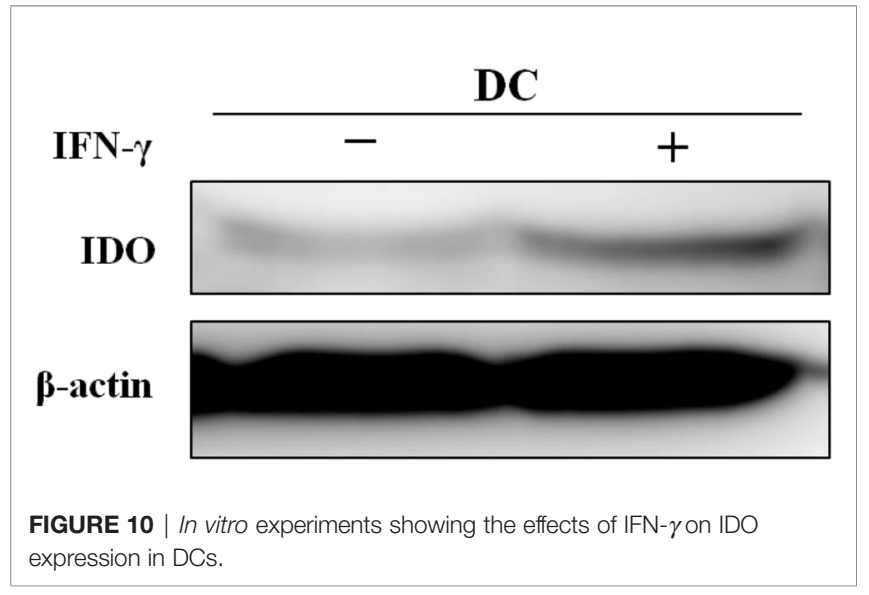

stimuli (12). The expression of their surface markers was not obviously affected in this study, suggesting the biological friendliness of the nanovector and the transfection process.

\section{In Vivo Homing of Indoleamine 2, 3- Dioxygenase siRNA-Laden Dendritic Cell Vaccines to Lymph Nodes Can Be Successfully Detected by Magnetic Resonance Imaging}

During the treatment of $4 \mathrm{~T} 1$ tumor-bearing mice with DCVs, MR imaging showed that IDO siRNA-laden DCVs that were injected into the murine left footpads successfully migrated to the draining lymph nodes after $48 \mathrm{~h}$, resulting in nodal enlargement and darkening of the MR signal in the central zone. The central

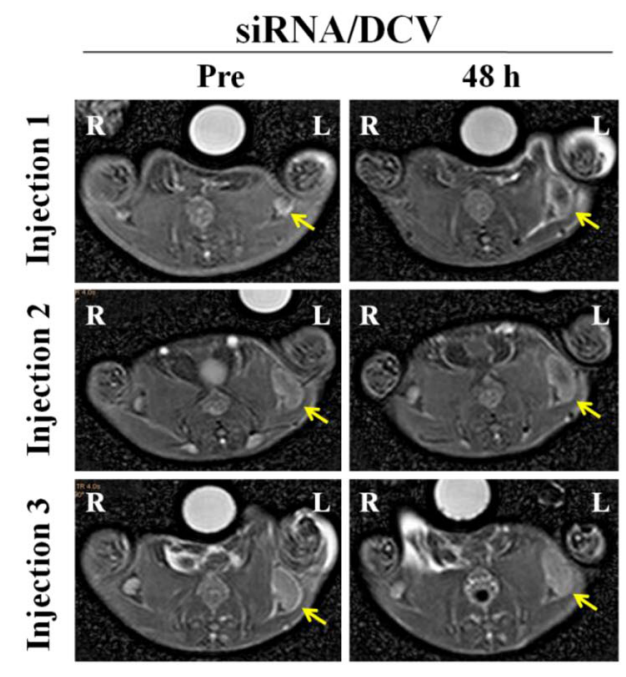

DC

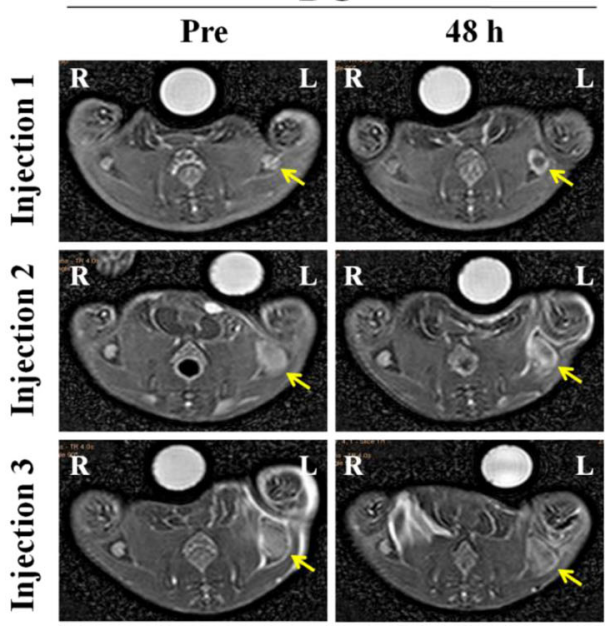

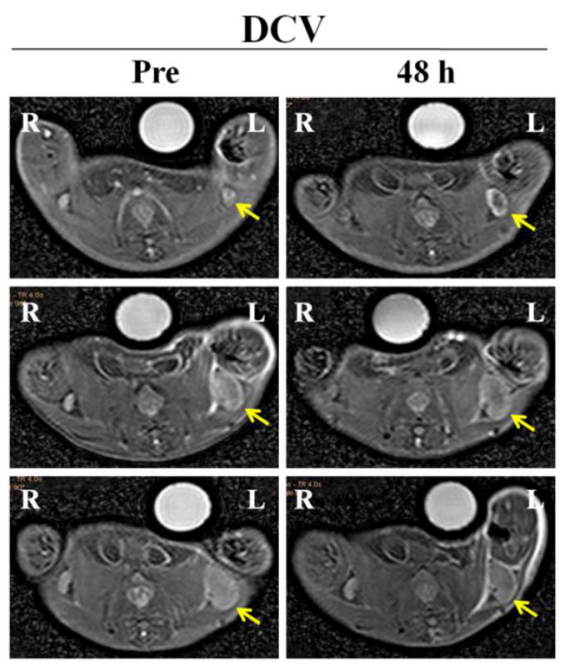

PBS

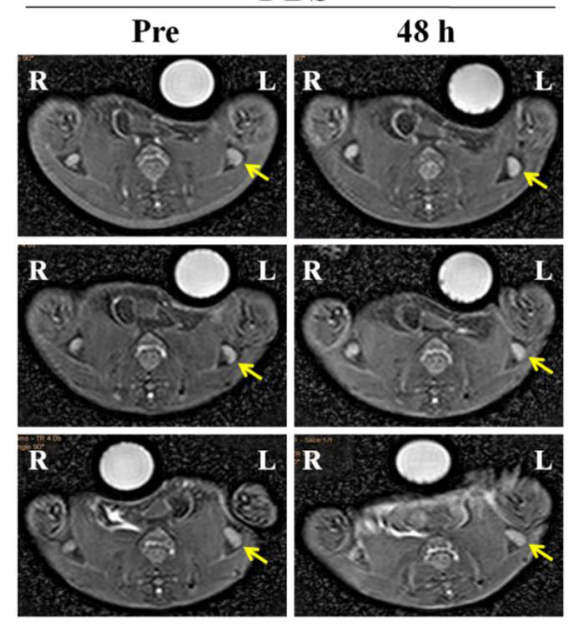

FIGURE 11 | The left hind footpads were injected three times (1 injection/week) with the siRNA/DC vaccine (siRNA/DCVs), DC vaccine (DCVs), DC or PBS. At $24 \mathrm{~h}$ after each injection, MR images of all groups but the PBS group showed decreased signals within enlarged popliteal lymph nodes (yellow arrows). 


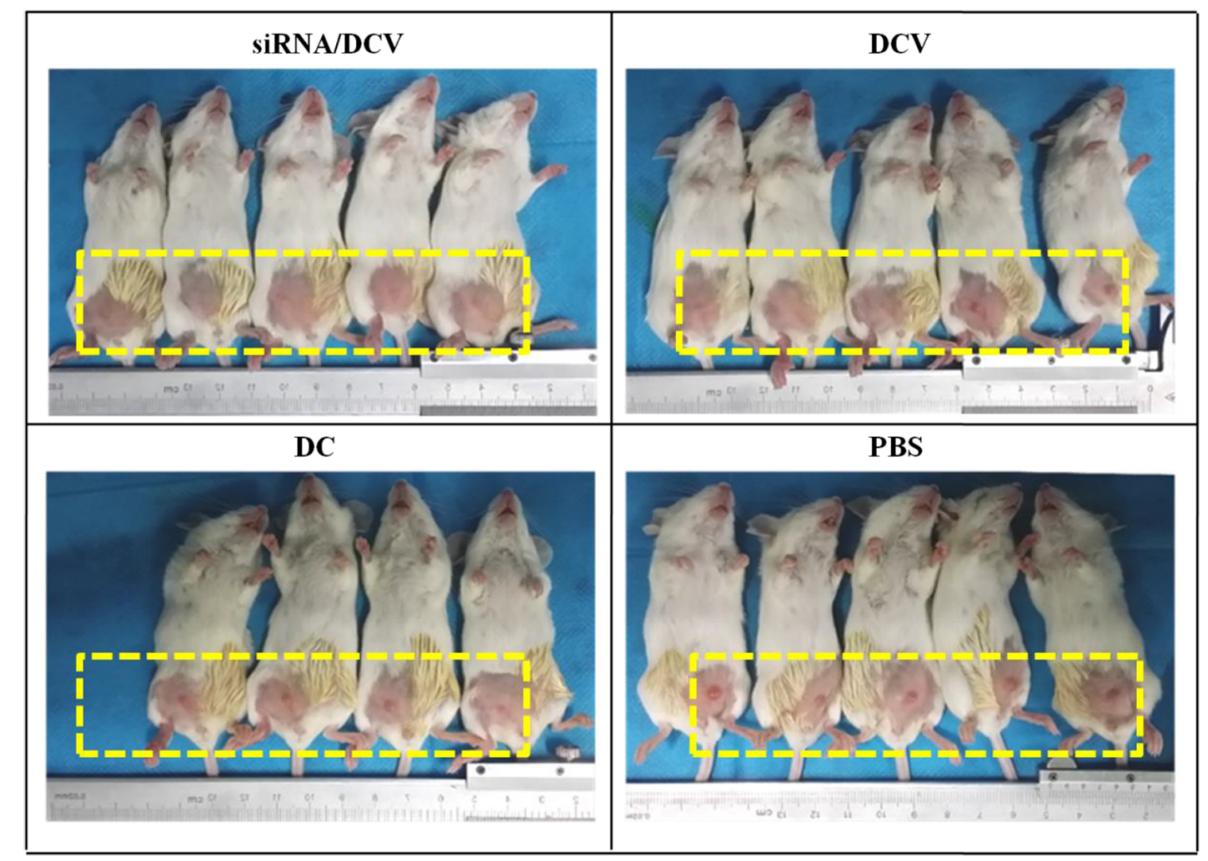

FIGURE 12 | Photos taken on the $6^{\text {th }}$ day after tumor cell inoculation. Tumors grew fastest in the PBS group, followed by the DC group and the two vaccine groups.

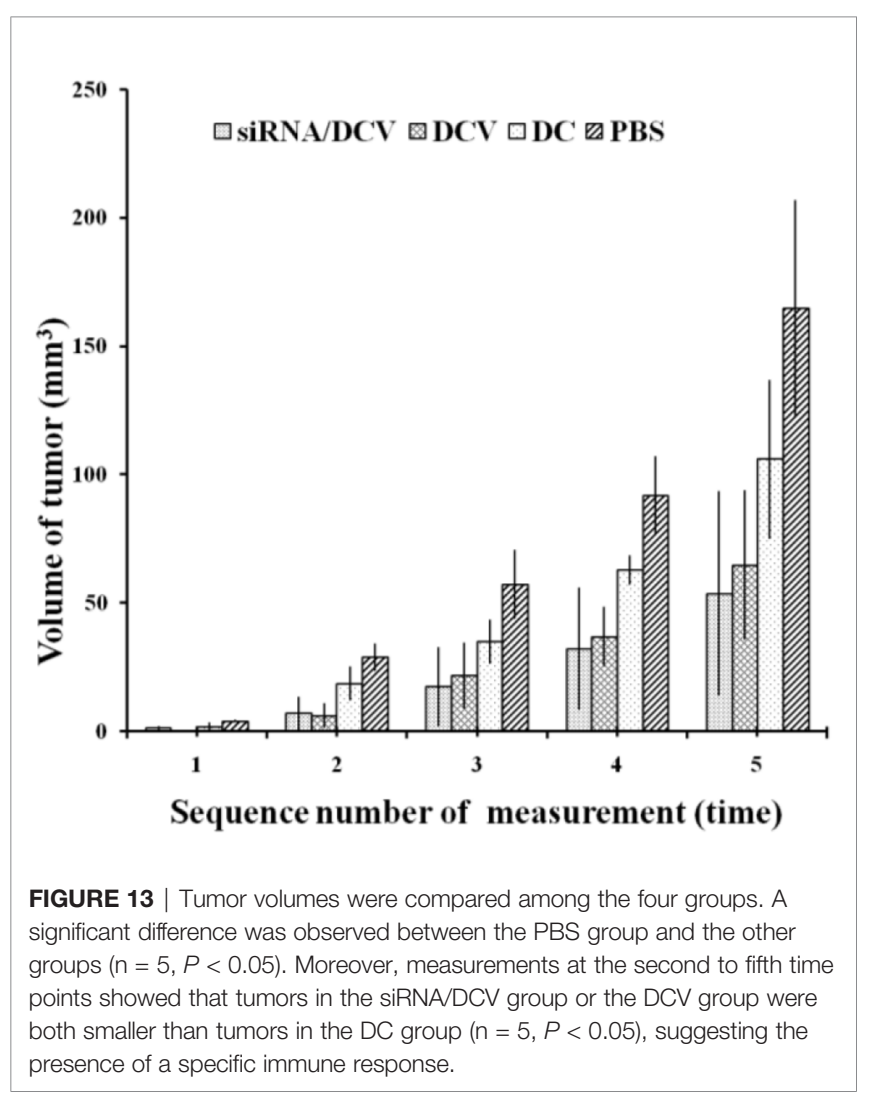

distribution indicates a decrease in the MR signal caused by active homing of the N-alkyl-PEI2k-LAC/SPIO nanocomposite containing DCVs rather than the nanocomposites themselves that are present mainly in the peripheral distribution (22). The tumor treatment adopted in this study mainly referred to the methodology reported by Hegmans JP (17). In the present study, regardless of the material that was injected, the tumors of the mice grew over time. However, the tumors of the PBS group grew fastest, followed by the DC group, indicating that both DCVs and IDO siRNA-laden DCVs actively inhibit tumor growth.

\section{Limitations of This Study and Possible Causes}

Notably, in contrast to previous reports, DCVs transfected with or without IDO-siRNA produced similar levels of tumor inhibition in the present study. No significant difference in tumor size was observed between the two groups $(23,24)$. This lack of a difference in the tumor size is a major drawback of the study, as tumor is presumed to be regulated by the low expression of IDO in DCs, as verified by our repeated experiments. Typically, IFN- $\gamma$ induction alone is sufficient to up-regulate IDO expression in DCs, but accumulating evidence showed that the up-regulation of IDO in DCs required 'two signals', i.e., IFN- $\gamma$ stimulation followed a second stimulus (such as IL-10, CD40 or LPS) $(25,26)$. In the present study, DCs underwent a two-stage stimulation with IFN- $\gamma$ and LPS, but to our surprise, the expression of IDO in DCs remained low. We have not yet determined a rational explanation for these outcomes but presume that they may be associated with the factors listed below. a) The subtype of DCs. The DCs cultured in this study were mainly cDCs, not pDCs, which may partially explain the low expression of IDO. b) The method used for DC 
culture. We cultured DCs mainly using the methodology reported by Lutz MB (27). Vaccines prepared using the method described by Lutz MB have been reported to exert the best anticancer effect (17). A good therapeutic effect may require IDO low expression. c) The microenvironment in which DCs reside. The DCs cultured in the present study were obtained from normal tumor-free mice. However, tumor-mediated modulation of the humoral immune environment has been reported to contribute to the up-regulation of IDO in DCs (28). Nevertheless, the main purpose of this study was to show that an IDO siRNA could be successfully introduced into DCs with lab-made gene nanovectors and used as in vivo imaging tracer. This purpose has been achieved. Moreover, our research group has previously used vectors in an analogous molecular skeleton to repeatedly confirm that the transfection of an siRNA with these vectors effectively silences the target genes in cells $(9,19)$. In subsequent studies, we plan to select more suitable targets such as PD-L, A20 and DIgR2 to verify the validity of siRNAmediated silencing.

\section{CONCLUSIONS}

In this study we used, with success, the lactoslyated nanocomposites $\mathrm{N}$-alkyl-PEI2k-LAC/SPIO as an MRI-visible gene nanovector for IDO siRNA transfection into DCs. After the IDO siRNA-laden DCVs were adoptively transferred to the mice with $4 \mathrm{~T} 1$ tumors, in vivo MR imaging clearly showed them homing into the draining lymph nodes. In summary, N-alkyl-PEI2k-LAC/ SPIO, a gene delivery system, is able to transfect nucleic acid fragments and track cell migration in vivo using MR imaging.

\section{REFERENCES}

1. Zhang S, Wang Q, Miao B. Review: dendritic cell-based vaccine in the treatment of patients with advanced melanoma. Cancer Biother Radiopharm (2007) 22:501-7. doi: 10.1089/cbr.2007.354

2. Zhang X, Gordon JR, Xiang J. Advances in dendritic cell-based vaccine of cancer. Cancer Biother Radiopharm (2002) 17:601-19. doi: 10.1089/ 108497802320970217

3. Munn DH, Sharma MD, Lee JR, Jhaver KG, Johnson TS, Keskin DB, et al. Potential regulatory function of human dendritic cells expressing indoleamine 2,3-dioxygenase. Science (2002) 297:1867-70. doi: 10.1126/science.1073514

4. Endo R, Nakamura T, Kawakami K, Sato Y, Harashima H. The silencing of indoleamine 2,3-dioxygenase 1 (IDO1) in dendritic cells by siRNA-loaded lipid nanoparticles enhances cell-based cancer immunotherapy. Sci Rep (2019) 9:11335. doi: 10.1038/s41598-019-47799-w

5. Yen MC, Lin CC, Chen YL, Huang SS, Yang HJ, Chang CP, et al. A novel cancer therapy by skin delivery of indoleamine 2,3-dioxygenase siRNA. Clin Cancer Res (2009) 15(2):641-9. doi: 10.1158/1078-0432.CCR-08-1988

6. Chen D, Koropatnick J, Jiang N, Zheng X, Zhang X, Wang H, et al. Targeted siRNA silencing of indoleamine 2,3-dioxygenase in antigen-presenting cells using mannose-conjugated liposomes: a novel strategy for treatment of melanoma. J Immunother (2014) 37(2):123-34. doi: 10.1097/CJI.0000000000000022

7. Chen Y, Wang W, Lian G, Qian C, Wang L, Zeng L, et al. Development of an MRI-visible nonviral vector for siRNA delivery targeting gastric cancer. Int J Nanomed (2012) 7:359-68. doi: 10.2147/IJN.S24083

8. Wang Z, Liu G, Sun J, Wu B, Gong Q, Song B, et al. Self-assembly of magnetite nanocrystals with amphiphilic polyethylenimine: structures and

\section{DATA AVAILABILITY STATEMENT}

The raw data supporting the conclusions of this article will be made available by the authors, without undue reservation.

\section{ETHICS STATEMENT}

All animal procedures were performed in accordance with the Guidelines for Care and Use of Laboratory Animals of North Sichuan Medical College, and experiments were approved by the Animal Ethics Committee of North Sichuan Medical College (P20191226).

\section{AUTHOR CONTRIBUTIONS}

$\mathrm{HA}$, as the consultant, was responsible for the guiding of the experimental research. YX took charge of the overall design of the project as well as the quality and schedule control. CW prepared and tested the MRI nanocomposites, and CW, WZ and RJ implemented the biological experiments. All authors contributed to the article and approved the submitted version.

\section{FUNDING}

This work was funded by the National Natural Science Foundation of China (81601490), Chongqing Science and Technology Foundation, and Chongqing Science and Technology Commission (cstc2018jscxmsybX0069 and cstc2016 shmszx130009).

applications in magnetic resonance imaging. J Nanosci Nanotechnol (2009) 9:378-85. doi: 10.1166/jnn.2009.j033

9. Lin G, Zhu W, Yang L, Wu J, Lin B, Xu Y, et al. Delivery of siRNA by MRIvisible nanovehicles to overcome drug resistance in MCF-7/ADR human breast cancer cells. Biomaterials (2014) 35:9495-507. doi: 10.1016/ j.biomaterials.2014.07.049

10. Shen T, Zhu W, Yang L, Liu L, Jin R, Duan J, et al. Lactosylated N-Alkyl polyethylenimine coated iron oxide nanoparticles induced autophagy in mouse dendritic cells. Regenerative Biomater (2018) 5:141-9. doi: 10.1093/rb/rbx032

11. Du J, Zhu W, Yang L, Wu C, Lin B, Wu J, et al. Reduction of polyethylenimine-coated iron oxide nanoparticles induced autophagy and cytotoxicity by lactosylation. Regenerative Biomater (2016) 3:223-9. doi: 10.1093/rb/rbw023

12. Xu Y, Wu C, Zhu W, Xia C, Wang D, Zhang H, et al. Superparamagnetic MRI probes for in vivo tracking of dendritic cell migration with a clinical $3 \mathrm{~T}$ scanner. Biomaterials (2015) 58:63-71. doi: 10.1016/j.biomaterials.2015.04.016

13. Sun SH, Zeng H, Robinson DB, Raoux S, Rice PM, Wang SX, et al. Monodisperse MFe2O4 ( $\mathrm{M}=\mathrm{Fe}, \mathrm{Co}, \mathrm{Mn}$ ) nanoparticles. J Am Chem Soc (2004) 126:273-9. doi: 10.1021/ja0380852

14. Steinman RM. Dendritic cells: understanding immunogenicity. Eur J Immunol (2007) 37 Suppl 1:S53-60. doi: 10.1002/eji.200737400

15. Akita H, Kogure K, Moriguchi R, Nakamura Y, Higashi T, Nakamura T, et al. Nanoparticles for ex vivo siRNA delivery to dendritic cells for cancer vaccines: programmed endosomal escape and dissociation. J Controlled Release Off J Controlled Release Society (2010) 143:311-7. doi: 10.1016/j.jconrel.2010.01.012

16. Jurgens B, Hainz U, Fuchs D, Felzmann T, Heitger A. Interferon-gammatriggered indoleamine 2,3-dioxygenase competence in human monocyte- 
derived dendritic cells induces regulatory activity in allogeneic T cells. Blood (2009) 114:3235-43. doi: 10.1182/blood-2008-12-195073

17. Hegmans JP, Hemmes A, Aerts JG, Hoogsteden HC, Lambrecht BN. Immunotherapy of murine malignant mesothelioma using tumor lysatepulsed dendritic cells. Am J Respir Crit Care Medicine (2005) 171:1168-77. doi: 10.1164/rccm.200501-057OC

18. Silva MA, Jury J, Sanz Y, Wiepjes M, Huang X, Murray JA, et al. Increased bacterial translocation in gluten-sensitive mice is independent of small intestinal paracellular permeability defect. Digest Dis Sci (2012) 57:38-47. doi: 10.1007/s10620-011-1847-z

19. Liu G, Xie J, Zhang F, Wang Z, Luo K, Zhu L, et al. N-Alkyl-PEIfunctionalized iron oxide nanoclusters for efficient siRNA delivery. Small (2011) 7:2742-9. doi: 10.1002/smll.201100825

20. Jia J, Zhang Y, Xin Y, Jiang C, Yan B, Zhai S. Interactions between nanoparticles and dendritic cells: from the perspective of cancer immunotherapy. Front Oncol (2018) 8:404. doi: 10.3389/fonc.2018.00404

21. Dong H, Wen ZF, Chen L, Zhou N, Liu H, Dong S, et al. Polyethyleneimine modification of aluminum hydroxide nanoparticle enhances antigen transportation and cross-presentation of dendritic cells. Int J Nanomed (2018) 13:3353-65. doi: 10.2147/IJN.S164097

22. Cho NH, Cheong TC, Min JH, Wu JH, Lee SJ, Kim D, et al. A multifunctional core-shell nanoparticle for dendritic cell-based cancer immunotherapy. Nat Nanotechnol (2011) 6:675-82. doi: 10.1038/nnano.2011.149

23. Flatekval GF, Sioud M. Modulation of dendritic cell maturation and function with mono- and bifunctional small interfering RNAs targeting indoleamine 2,3-dioxygenase. Immunology (2009) 128:e837-48. doi: 10.1111/j.13652567.2009.03093.x

24. Sioud M, Saeboe-Larssen S, Hetland TE, Kaern J, Mobergslien A, Kvalheim G. Silencing of indoleamine 2,3-dioxygenase enhances dendritic cell immunogenicity and antitumour immunity in cancer patients. Int J Oncol (2013) 43:280-8. doi: 10.3892/ijo.2013.1922

25. Yanagawa Y, Iwabuchi K, Onoe K. Co-operative action of interleukin-10 and interferon-gamma to regulate dendritic cell functions. Immunology (2009) 127:345-53. doi: 10.1111/j.1365-2567.2008.02986.x

26. Jung ID, Lee JS, Lee CM, Noh KT, Jeong YI, Park WS, et al. Induction of indoleamine 2,3-dioxygenase expression via heme oxygenase-1-dependant pathway during murine dendritic cell maturation. Biochem Pharmacol (2010) 80:491-505. doi: 10.1016/j.bcp.2010.04.025

27. Lutz MB, Kukutsch N, Ogilvie AL, Rossner S, Koch F, Romani N, et al. An advanced culture method for generating large quantities of highly pure dendritic cells from mouse bone marrow. J Immunol Methods (1999) 223:77-92. doi: 10.1016/s0022-1759(98)00204-x

28. Kuales MA, Wenzel J, Schmid-Wendtner MH, Bieber T, Von Bubnoff D. Myeloid CD11c+S100+ dendritic cells express indoleamine 2,3dioxygenase at the inflammatory border to invasive lower lip squamous cell carcinoma. Histol Histopathol (2011) 26:997-1006. doi: 10.14670/ HH-26.997

Conflict of Interest: The authors declare that the research was conducted in the absence of any commercial or financial relationships that could be construed as a potential conflict of interest.

Copyright $\odot 2021 \mathrm{Wu}$, Zhu, Jin, Ai and Xu. This is an open-access article distributed under the terms of the Creative Commons Attribution License (CC BY). The use, distribution or reproduction in other forums is permitted, provided the original author(s) and the copyright owner(s) are credited and that the original publication in this journal is cited, in accordance with accepted academic practice. No use, distribution or reproduction is permitted which does not comply with these terms. 